Article

\title{
Knowledge-Intensive Entrepreneurship and S3: Conceptualizing Strategies for Sustainability
}

\author{
Ethan Gifford *(D) and Maureen McKelvey \\ Department of Economy and Society, University of Gothenburg, 40530 Gothenburg, Sweden \\ * Correspondence: ethan.gifford@gu.se
}

Received: 30 June 2019; Accepted: 1 September 2019; Published: 4 September 2019

check for updates

\begin{abstract}
Smart specialization strategies represent public policy initiatives to develop regions based on new combinations of knowledge and industries. The aim of this article is to enrich the theory and practice of smart specialization strategies (S3) by integrating the conceptualization of knowledge-intensive entrepreneurship (KIE). We propose that knowledge-intensive entrepreneurship is necessary in order to specify how public and private support of KIE firms can be beneficial to develop new knowledge relevant to the fulfillment of specific sustainable development goals. We did so by further developing a conceptual model of innovation governance routines by integrating sustainability goals. We also illustrated our conceptual model through two case studies from the Swedish maritime cluster. By extrapolating from the combination of the conceptual model and two case studies, we make three propositions about the different strategic roles that KIE firms can play within a broader S3 policy setting, and in such a way as to promote sustainability-related outcomes.
\end{abstract}

Keywords: entrepreneurship; innovation; knowledge-intensive sectors; smart specialization; sustainable development goals

\section{Introduction}

Smart specialization strategies represent public policy initiatives to develop regions based on new combinations of knowledge and industries. The aim of this article is to enrich the theory and practice of smart specialization strategies (S3) by integrating the conceptualization of knowledge-intensive entrepreneurship (KIE). We propose that knowledge-intensive entrepreneurship is necessary in order to specify how public and private support of KIE firms can be beneficial to develop new knowledge relevant to the fulfillment of specific sustainable development goals. In describing and analyzing two case studies, we also illustrate how the integration of an understanding of KIE by policy actors, researchers, and industry professionals can be beneficial to fulfillment or furthering of sustainable development. We address how innovations commercialized through the process of knowledge-intensive entrepreneurship have a positive role for social attainment of sustainable development outcomes, and how different strategic possibilities for the KIE firm and public policy can enhance smart specialization and sustainability-related outcomes. By doing so, we build on the S3 and KIE streams of literature. We outline how and under what circumstances KIE/S3 activities might be designed in order to enhance the fulfillment of sustainable development goals (SDGs) of the EU, moving into the decades to come.

Our contribution is to specify how and why there is a need for a concept like knowledge-intensive entrepreneurship to be introduced into the $\mathrm{S} 3$ discourse. The onset of research advocating transformative innovation policy and sustainable development reinforces this view. This is because KIE conceptualizes entrepreneurial activity with the potential to make social impact regardless of whether it materializes in high-tech, low-tech, service-dominated, or creative industries [1-3]. The resilience of the concept is arguably a crucial asset to the overall need for adaptability to local context that is present in smart 
specialization policy making, since S3 argues for many specific types of entrepreneurial action, but it is less clear conceptually what types of ventures should act, and how.

The structure of the article is as follows. Section 2 reviews the concept of smart specialization. Section 3 introduces the concept of knowledge-intensive entrepreneurship and proposes how and why the two concepts can, when combined, constitute a more nuanced understanding of the entrepreneurship dimension of smart specialization strategies. Section 4 proposes an adapted conceptual framework based on McKelvey, Zaring, and Szücs [4]. Section 4 provides an illustrative case of systemic interaction between KIE entrepreneurs, public policy, and regional actors in creating a fertile environment for one type of sustainable development in West Sweden's traditional industries of marine energy and aquatic food production. Section 5 draws conclusions and suggests avenues for future research.

\section{Smart Specialization Strategy}

"A more promising strategy appears to be to encourage investment in programs that will complement the country's other productive assets to create future domestic capability and interregional competitive advantage. We had termed this strategy "smart specialization"". Dominique Foray, p. 818 [5]

Smart specialization is a mission-oriented policy strategy that has become an important and widely used framework for policy makers at the international, national, and regional levels. Not least within Europe, public policy makers use S3 strategies in order to identify industrial assets at the regional level, with the end goal of finding ways to strategically utilize these assets in order to maintain and increase competitiveness.

So far, smart specialization theory has been built up around, and largely taken into account, the key roles of established small and medium-sized enterprises (SMEs) and newly founded enterprises in the S3 constellation [6]. However, though it is acknowledged that finding "ways to link new technologies and activities to as wide a range of sectors and activities is critical" [6] (p. 538), this literature is lacking a more detailed conceptualization of the knowledge-intensive entrepreneur or entrepreneurial firm that fits with the specific goals of S3.

An integral component of the smart specialization strategy is sustainable growth and development [7]. Several streams of literature [8-10] have heavily influenced modern policy discourse about sustainability in Europe-and specifically about the role of technology and institutions in promoting transition. Rather than focusing on technology per se, this type of social science research aims to discuss how systemic transition towards sustainability addresses the overall changes needed in society, and especially the role of public policy [11]. It is moreover recognized that an independent technology will only contribute to sustainability goals when complementary technologies and institutions also become available in this larger sociotechnical system [12]. Related literature on public policy conceptualized as grand societal challenges and mission-oriented policy argues that major society challenges—-such as sustainability, aging, healthcare, climate change, energy, and poverty-will require new modes of collaboration between public and private actors [13,14]. However, current knowledge about how this can be done is not adequate, and therefore, investment into developing new technology and new scientific knowledge will be needed in order to solve current and future challenges.

Past models of innovation policy were developed with the purpose of strengthening the systemic interactions between so-called new technology-based firms and other actors, though this has widely been acknowledged to tell only a portion of the story. Revitalizing and reappraising the potential of existing and established industries and their perceived technological upgrading through smart specialization at the regional and national level has been thrust to the forefront of the policy agenda [15]. In addition, creative and cultural industries play a decisive role in the development of regions and in selecting and identifying socially desirable outcomes to strive for [16].

However, the literature has not been clear in answering the following question: What types of startups are needed in an S3 area? The answer to this question is key to the success of the S3 strategy both regionally and internationally as a cohesive whole. We want to avoid the type of entrepreneurship 
that ends in burned resources with little tangible economic impact and instead to focus on the type of entrepreneurship that has the potential to positively impact productivity [17]. Current S3-related literature acknowledges the importance of looking outside high-tech industries for regional competitive advantage [5,18], but this lacks specificity and a clear conceptualization.

In her review of smart specialization policy instruments 10 years on, Uyarra [19] identified the entrepreneurial discovery process through which entrepreneurs help to identify what in her view are ideal directions for specialization [15] (p. 7) [20] and emphasized its importance as a key aspect of how to reframe S3. She pointed to the fact that the policy-led process of designing strategy for actors, with its focus on strengthening relationships between actors at the regional level, has often eclipsed the actual implementation of strategy. She identified a lack of focus regarding the actual implementation of strategies and coordination and bringing together of regional actors, calling for an increased importance of observing and understanding agency of both policy makers and 'product champions'. Thus, we suggest it is crucial to understand how these entrepreneurs construct and carry out their strategies in detail, as well as how they adapt to societal transitions toward sustainability and to the changing rules of the game in order to gain or maintain competitiveness.

Foray [18] (p. 1507) defined transformative activities as a 'collection of innovation capacities and actions that have been 'extracted', as it were, from an existing structure [or structures], to which can be added extra-regional capacities and which is oriented towards a certain structural change'. Transformative activities play a key role in implementing an S3 [21], and as Foray [5] pointed out, their development can occur spontaneously and successfully. This is a process, he argued, of combining the capabilities of entrepreneurial actors with those of the understanding and vision of industry actors. However, in many instances, the capabilities of the entrepreneurial actors are underdeveloped and thus unable to manifest the necessary critical mass to drive the process forward. Or, potentially, the collective action required by the 'market' is simply too great a task. As he put it, '[a] policy is required to help identify an transformative activity that is needed to trigger a structural change and support the growth of such activity' [5] (p. 819). Moreover, Foray [22] argued that systemic bias towards high-tech entrepreneurship and innovation should be avoided in construction of transformative activities.

"The goal is therefore twofold: to encourage young innovative firms by equipping their ecosystem with all of the necessary capabilities AND to address the innovative complementarities between the high-tech industry and traditional sectors. [ ... ] [I]t will address many barriers and obstacles to innovation diffusion in a traditional sector. If this is not done, the activity will remain limited to start-ups, and it will lose its truly transformative nature." [22] (p. 12)

Here he arguef that 'the [transformative] activity must also integrate actions that allow the adoption of high technology by the sector that will be a potential user' [22] (p. 12). This valuable insight also relates to Schot and Steinmeuller's [9] characterization of new technology-based firms as having the role of 'fostering innovation' in their depiction of their innovation for growth framing. In the same article, entrepreneurship was referenced as playing a sizable role in the brokering of scientific and technical knowledge within an innovation systems approach. Additionally, they discussed the process of transformative change, by way of which they argue that 'existing R\&D and national systems of innovation frames for science, technology and innovation policy are unfit for addressing the environmental and social challenges [facing the modern state]. [9] (p. 1562).' Within this context, they outlined the need to focus on innovation as search on a systemic level, which is then led by the social and environmental objectives of the day. They argued that transformative change must take into account societal demand for innovation and for change, and they explicitly emphasized the role of the entrepreneur by way of the user, the legitimator, and the social lobbyist in constructing and exploring demand and market spaces. Individuals with capabilities, in other words, will be required to 'bridge social and scientific and technological domains [9] (p. 1564)'. This means that policy needs to facilitate the encouragement of young innovators to provide capabilities to their sector or industry from higher 
knowledge activities, as well as creating and maintaining innovation complementarities between high and low tech. The modern dilemma of grand societal challenges is in effect a collective action problem, since the outcomes deal with knowledge whose benefits are simply not appropriable by one inventor, or nation, alone. This leads to the assertion that the probability of a solution arising from the market alone is considerably low [23], and hence, government needs to be involved and aware of the decisions driving strategic action of these young innovators, i.e., KIE firms.

Another related ongoing discussion is that of smart specialization strategies stemming from a more economic geographic point of view, involving dilemmas such as related vs. unrelated diversification of regions, as well as the balance between relatedness density and knowledge complexity of regional agglomerated technologies [24,25]. Studies with this focus have made recommendations for a more bottom-up-oriented approach for smart specializations by drawing upon the aforementioned relationships, and evidence shows that implementation at the regional level often lacks methodological tools to effectively implement interregional links between technological domains. This type of focus is deemed to have the potential to uncover existing but unknown, as well as unrealized, technological opportunities, as well as to assess the role of entrepreneurial discoveries in S3-focused regions [24,26]. This provides further assertion to our position that it is critical to understand the strategic motivations of knowledge-intensive entrepreneurs in an S3 area.

Thus, the smart specialization policy and academic debate touch upon many streams of literature which stress the importance of knowledge for economic growth and societal welfare. The National Systems of Innovation concept developed in the 1990s heavily influenced the Organization for Economic Co-operation and Development (OECD) and its member countries' public policy for science and technology [27]. Innovation systems were promoted as conceptualization for the importance of new knowledge, as well as stimulated the developments of many indicators to measure knowledge and innovations. A related but somewhat later development was to focus not only on R\&D and manufacturing but also service, which was popularized through the notion of KIBS, knowledge-intensive business services [28].

What should be clear by now is that there is much at stake as well as much to gain with smart specialization strategies. We argue that by identifying and classifying different strategic actions of KIE firms and what drives these actions within an S3 area, policy makers can then make a more holistic assessment of the role of these firms and how to best support these firms in order for new sustainable innovations to materialize. Moreover, they need to ensure that these unique firms contribute the maximum possible benefits to the system in which they are active.

\section{Proposing a Specific Knowledge-intensive, Innovative Perspective on Entrepreneurship within S3}

Knowledge-intensive entrepreneurship (KIE) is an established empirical and theoretical phenomenon thanks to EU projects, edited scientific books, and peer-reviewed scientific journals $[2,29,30]$. Its proponents have argued in national policy and research communities that understanding it more fully can lead to tangible ways to increase productivity and positively influence economic growth in developed and developing countries and sectors. KIE goes beyond strict sectoral classification of what constitutes high impact or high potential entrepreneurship. This type of entrepreneurship materializes within as well as outside of high-tech or highly research-intensive sectors and has been linked to EU and OECD initiatives as a key area for development. While this literature conceptualizes the whole entrepreneurship process as KIE, in order to measure and make more specific empirical studies, one must focus on how individuals start projects and firms, in close interaction with their environment, or innovation system, known as a KIE firm. To summarize by way of Malerba and McKelvey's [2] (p. 6) definition, KIE firms are “... new learning organizations that use and transform existing knowledge and generate new knowledge in order to innovate within innovation systems". 
Further study of this topic by policy actors can lead to increased potential for learning lessons from existing entrepreneurial innovation systems and how they have developed and applying these lessons to other contexts, for instance, sustainable development of industry in other economies. It conceptually links Schumpeterian entrepreneurship, evolutionary economics [31], and innovation systems theory in order to create a synthetic concept to understand and taxonomize societally beneficial forms of entrepreneurship that have their basis in the advanced use and application of scientific, technological, or creative knowledge [2,32].

We want to emphasize that this interplay between new firms, old firms, and the state cannot be limited to high tech industries [5]. As has been reviewed in the previous section, recent attempts to improve S3 argue that it should focus more on interactions between different actors and less on a specific trajectory [24], while at the same time focusing on the actual implementation of the strategy [19].

We propose that this private actor role in implementing S3 on a local/regional level can be in part filled by this particular actor/firm [2]. KIE includes entrepreneurial firms that use different types of advanced knowledge and innovation to compete and may be found in low-, medium-, high-tech, and service sectors. Our argument is that these firms play a crucial role in today's evolving industrial landscape, not least in the EU region, where strategic actions by multinational firms must be made to fit with overall strategies of regional policy, and wherein innovation occurring in and through these firms constitutes a direct action towards fulfillment of sustainable development goals.

Integrating a KIE perspective into this constellation of actors and actions is crucial, because by doing so, we can understand more about the needs and drivers of startups when balancing between different alternative models of interaction within their systemic context, and how these decisions shape different paths and outcomes for the region (or country). Additionally, different types of engagement with universities and public actors, either directly through commercialization activities or indirectly through more intangible academic engagement, can result in higher likelihood of innovation in different sectors ranging from low- to high-technology areas [33]. Moreover, according to public policy, the societal goal of sustainability should be met through new scientific and technological knowledge, as well as goals of promoting industrial competitiveness and high-impact research. KIE firms thus fill a key role as creators and users of new scientific and technological knowledge.

Here we address the fit between strategies of small KIE firms and regional smart specialization strategies for developing new scientific and technological knowledge. This is because even though much of this stream of literature suggests different types of collaborations are needed, few address it conceptually. Hence, the purpose of this article is to argue how and why KIE should be introduced specifically into these policy debates and literature on S3, as they in our view currently have an underdeveloped view of what types of entrepreneurship are needed. Hence, we are arguing that smart specialization strategies need to take into account and understand the specific importance of low-tech or mid-tech KIE ventures which can use and apply relevant scientific and technological knowledge in their business activities and are thus more likely to transfer a higher portion of technology and skills to traditional industries, which has been pointed out as lacking in the literature [30].

Our proposed conceptual model of innovation governance routines starts by building upon that conveyed in McKelvey, Zaring, and Szücs [4] regarding governance of collective action in science and technology in the context of knowledge-intensive entrepreneurship (see Figure 1).

This conceptual model for innovation governance routines draws on the idea that the development of new science and technology cannot in and of itself produce an economic impact. This is the role of actors on the individual and organizational level to carry out through innovation and entrepreneurship activities, which in turn are achieved through idiosyncratic routines and capabilities [4]. The model by McKelvey, Zaring, and Szücs initially takes inspiration from the concept of collective action associated with the now famous Ostrom [29] model but develops a new model for innovation governance routines. KIE firms act upon innovative opportunities produced through collective action [34] for science and technology, which are legitimized through norms, incentives, and institutions. This leads to spillovers into new areas of public knowledge which are producing both private returns (for the KIE firms) as 
well as public returns for society (granting that the KIE firms are actually producing novel uses and applications of science and technology aimed towards solving society's problems). The following quote succinctly summarizes the model:

“New scientific and technological knowledge continues to be developed through collective action. Some results continue to remain public knowledge and provide public returns through the new body of knowledge while other results are translated through innovation and entrepreneurship into private returns". McKelvey, Zaring and Szücs [4] (p. 15)

The collective action of science and technology refers to the role played by KIE firms in their invention, use, application or commercialization of new scientific and technological knowledge, or their collaboration in these specialized activities. This can naturally occur in diverse sectors and can be crucial in smart specialization-related industries from a regional perspective. Norm, incentives, and institutions play a reciprocal role in transferring this new science and technology into the realm of public knowledge, where a local or regional populous is aware of the development and the inventions or applications can find a market, resulting in successful innovation. This comes about through collective action processes (See McKelvey, Zaring, and Szücs [4]), which could be approximated through wide-reaching collaborative programs spanning private and public sector actors. Norms and incentives play a key role in ensuring commitment to the collective action as well as regulating commons-related problems like free riding or the tragedy of the commons (ibid.). This, coupled with a dynamic monitoring process which assesses the changing conditions and needs of the market and the technology adoption by the market leads to the combination of public and private returns, leading in turn to increased progression towards sustainable development goals. Our argument is that through governance of knowledge-intensive entrepreneurship, public and private returns dually contribute to SDG fulfillment, which then reinforces the model through the link from SDGs back to collective action, the latter being made possible by the smart specialization framing present at a given regional level.

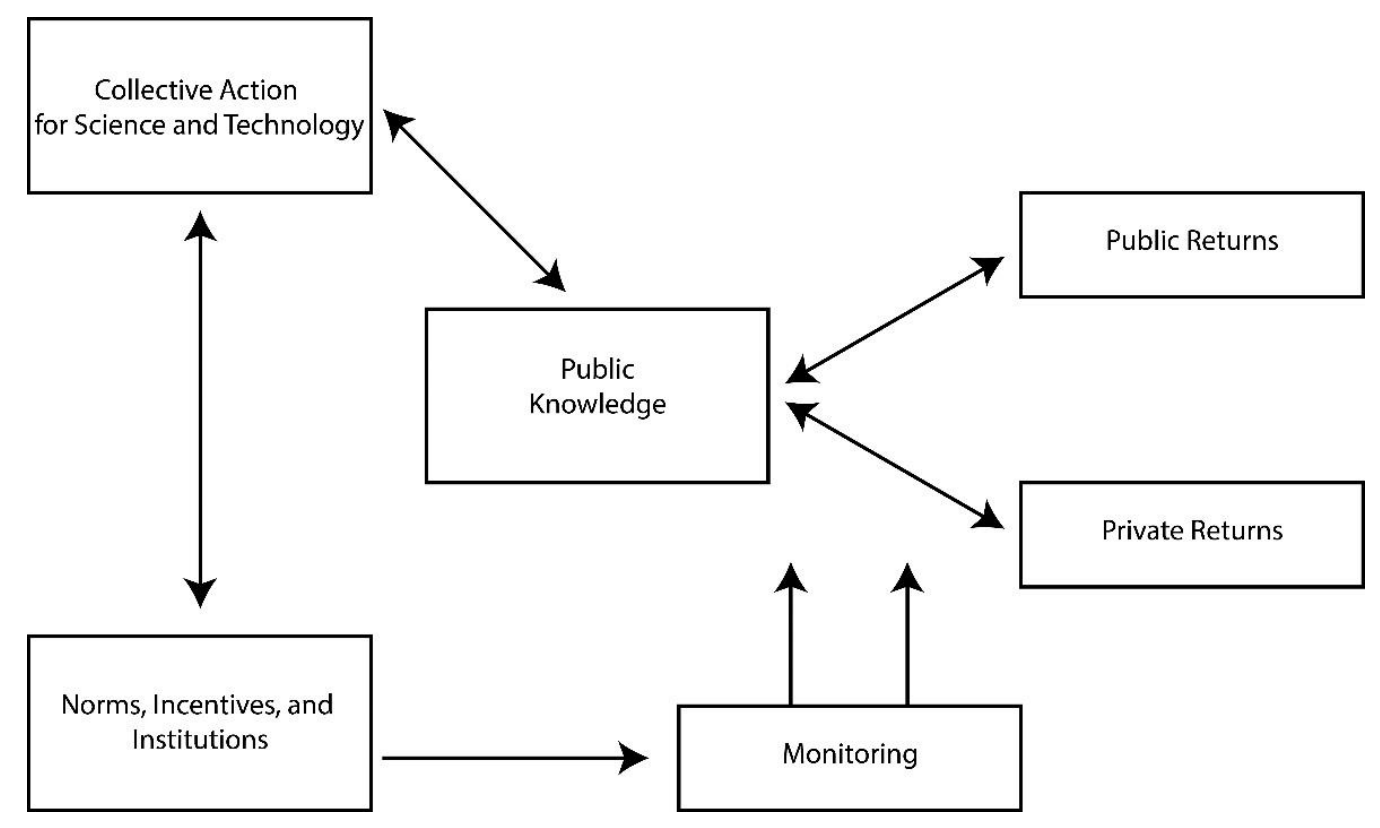

Figure 1. Conceptual model of innovation governance routines-adapted from McKelvey, Zaring, and Szücs [4].

Thus, to further develop this argument, we specify that the KIE concept should be integrated into S3 because it accounts for exactly what types of entrepreneurship are needed in S3 systems in order for them to actually have the proposed innovative impact on industries and regions. While it has been acknowledged that entrepreneurial action is crucial for the success of S3 policy, it is yet 
unclear in the literature exactly what type of entrepreneurship may be needed for differing regional (or system-based) configurations of resources and capabilities. The strength of KIE is in its flexibility and its resilience. The concept covers all types of innovative entrepreneurial economic activity with high potential to impact society and is not limited to sectoral constraints of traditional classifications of entrepreneurial firms. It is a synthetic and malleable concept whose core principles remain regardless of application area.

Our new proposed conceptual model of innovation governance routines is as follows. We took the KIE innovation governance model conveyed in Figure 1 model as a point of departure in our conceptualization and integrated it into the dual context of smart specialization and sustainability. Our revised conceptual model is shown in Figure 2.

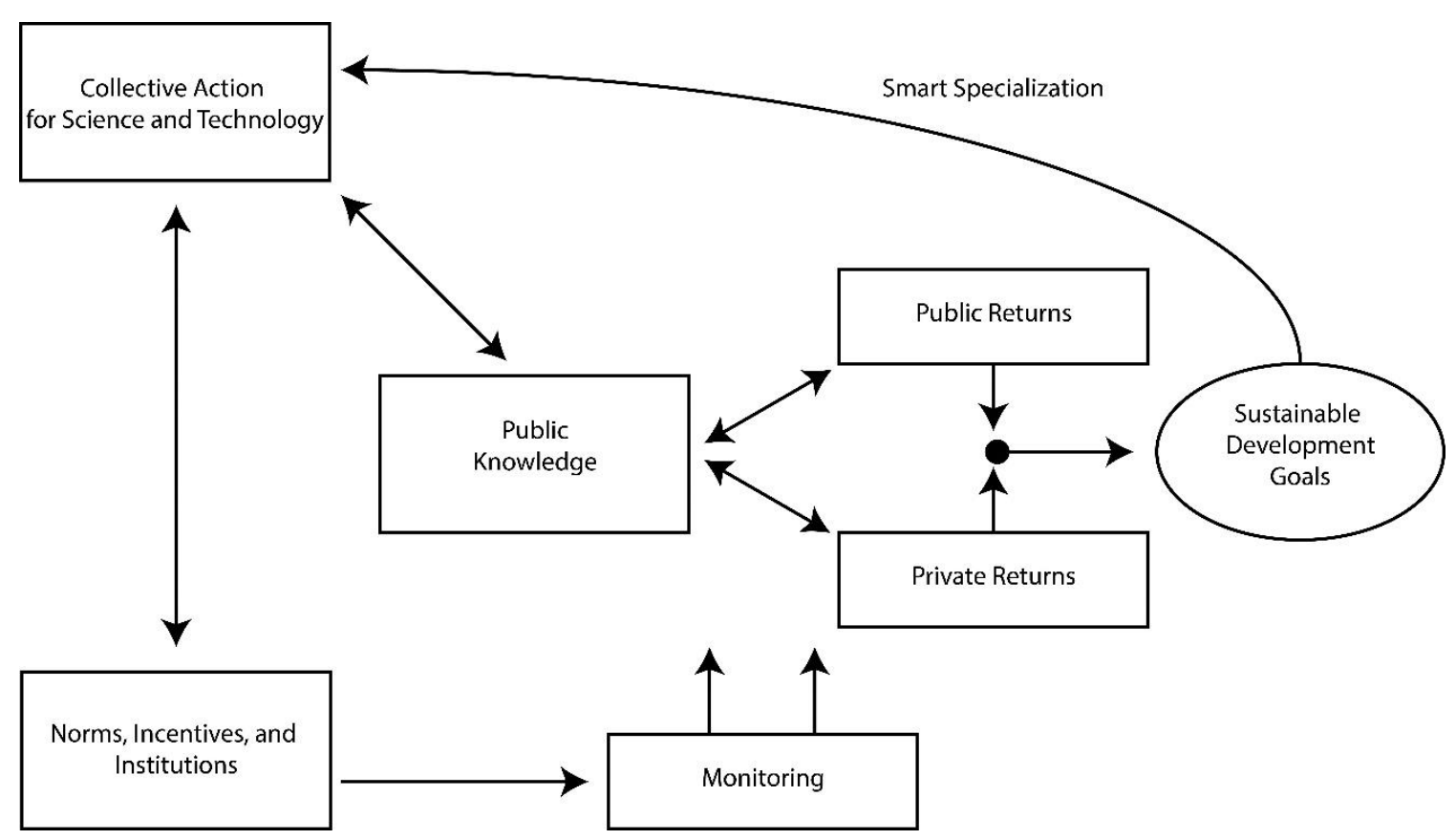

Figure 2. Knowledge-intensive entrepreneurship (KIE) governance within a smart specialization strategies (S3) system, addressing and subsequently drawing from sustainable development goals (SDGs).

Our proposed modified conceptual model for innovation governance routines thus provides a framework of understanding how KIE interacts with public and private systems within an industrial, regional, or sectoral context. In this instance, we applied and further developed to better analyze developments in a smart specialization area, i.e., we saw that the whole process model may occur within a specific S3 area or industrial system. The sustainability outcome is a direct outcome of the realized combination of public and private returns, the latter occurring when KIE entrepreneurs actually profit from their exploitation of innovative opportunities within S3 areas. Our view is that the public returns combined with the private returns of the firms are leading to increased likelihood of the fulfillment of SDGs. The feedback link between the SDGs and the collective action is made possible by the smart specialization focus. This focus basically allows for a concentration of resources into the entire sector/region and provides a backdrop for the different processes and effects conveyed in the model.

Seen through this analytical model, this means that this S3 area thus creates a possibility for experimentation by knowledge-intensive entrepreneurship, both in terms of generating the incentive for collective action for science and technology, as well as through the norms and institutions that ratify the existence of the types of solutions being offered by these KIE firms. In the next section, we describe 
and analyze two case studies, which illustrate how and why this conceptual model helps us to better understand S3 policy goals.

\section{The Maritime Cluster in West Sweden}

In order to illustrate how this type of activity, and the role of KIE, can take shape, we refer to an example in West Sweden, namely, the maritime cluster in this area. This area contains Gothenburg, Sweden's second largest city, and much of the Western Swedish coastal area. This particular cluster has come about as a direct result of smart specialization strategy at the policy level, and through multiple rounds of applications down to the regional level. The local municipal actor, Västra Götalands Region (VGR), facilitates the S3 program Sustainable Maritime Industries, distributes funding for projects, and acts as a central figure in organization of the cluster activities through maintenance and development of maritime expertise and competitiveness, cooperation across sectors, and involvement in multilevel maritime agendas [35]. These activities relate directly to the sustainable development goals (SDGs) of the UN, specifically Goal 14: Life below water, i.e., to conserve and sustainably use the oceans, seas, and marine resources for sustainable development.

The program, under the key organizational body overseeing collaborative efforts in this area, the Maritime Cluster in West Sweden, is composed of 6 different strategic groups: marine energy; marine governance; maritime operations and marine technology; tourism and recreation; marine biotechnology; and marine foods. The KIE entrepreneurs acting within this 'low-tech', i.e., traditional, sector collaborate with localized venture seed funding providers such as Almi, Västra Götaland Region, and the venture capital arms of the local universities, Chalmers School of Technology and the University of Gothenburg, along with other public and private actors. Two interesting strategic areas in this cluster are the marine foods group and the marine energy group. These groups were selected due to their observed positioning within the S3 area as having a high frequency of entrepreneurial actors present, as well as their roots in traditional, low-to-medium tech industrial activity, which over time has seen increase application and use of advanced scientific and technological knowledge. This development is a cornerstone of the KIE concept.

The marine foods group concerns maritime technologies and their application to nutrition and food production. The seafood group involves the area of biomarine food production and aquaculture, wherein fish, crustaceans, mollusks, and algae among other organisms are cultivated or used as a means of developing food, bio-based material, fuels and other resources for human use and consumption. Within this area, a continued regionally orchestrated collaborative effort has been ongoing between entrepreneurs, science departments at both universities and private organizations, along with regional and national innovation support offices and other public actors. This has yielded noteworthy results in establishing the financial and political support needed to provide "blue entrepreneurship" with the required resources and capabilities to establish both innovative and climate-friendly solutions in the future in West Sweden [36]. Table 1 shows a non-exhaustive list of the KIE firms that are active in each of the sectors, along with their key activities.

The marine energy group is broken up into four specialized sub-groups: oil and gas; sea energy; sea-based wind energy; and marine bioenergy (which overlaps with marine foods and biotechnology to some extent). Here as in the marine foods group, there is an orchestrating actor, Offshore West, that works within the regional innovation system in order to connect actors and facilitate processes to drive forward the collaborative projects in both national and intra-EU financed projects [36].

The way in which the entrepreneurial ventures in these subclusters relates to multinational enterprises and large private entities within the S3 area is also worth noting. In the marine foods group, many firms play a similar role in that they are actively developing new feed solutions based on science and technology, whether it is developing and applying biological feed and farming techniques for aquaculture (Smögenlax Aquaculture, Vegafish), waste-free food and consumer product production (Swedish Algae Factory), or developing solutions for scalable circular production (Ostrea Aquaculture). 
There are also firms active in consulting services helping other actors to become more sustainable in their production techniques (RAS 365) [36].

Table 1. KIE firms in two maritime sectors.

\begin{tabular}{|c|c|c|c|}
\hline \multicolumn{2}{|c|}{ Marine Foods } & \multicolumn{2}{|c|}{ Marine Energy } \\
\hline KIE Firm & Product/Service & KIE Firm & Product/Service \\
\hline Vegafish & $\begin{array}{l}\text { Shrimp farming without } \\
\text { antibiotics based on probiotic } \\
\text { environment feed techniques. }\end{array}$ & SeaTwirl & $\begin{array}{c}\text { Floating offshore wind power } \\
\text { solutions }\end{array}$ \\
\hline $\begin{array}{c}\text { Smögenlax } \\
\text { Aquaculture } \mathrm{AB}\end{array}$ & $\begin{array}{l}\text { Landbased aquaculture using } \\
\text { recirculated systems (RAS) and } \\
\text { biogas production. }\end{array}$ & Hexicon & $\begin{array}{c}\text { Floating offshore wind power } \\
\text { solutions }\end{array}$ \\
\hline $\begin{array}{l}\text { Swedish Algae } \\
\text { Factory }\end{array}$ & $\begin{array}{l}\text { Circular algae cultivation; } \\
\text { controlled algae bloom } \\
\text { producing shell materials for } \\
\text { multiple application areas. }\end{array}$ & Roxtec & $\begin{array}{l}\text { Sealing solution technology } \\
\text { including pipe and } \\
\text { cable-based solutions. }\end{array}$ \\
\hline RAS 365 & $\begin{array}{l}\text { Consultancy company with area } \\
\text { recirculation aquaculture system } \\
\text { implementation. }\end{array}$ & Greenpipe & $\begin{array}{l}\text { Sealing solution technology } \\
\text { including pipe and } \\
\text { cable-based solutions. }\end{array}$ \\
\hline Ostrea Aquaculture & $\begin{array}{l}\text { Oyster farming through } \\
\text { tech-intensive hatch production } \\
\text { at Koster national park in West } \\
\text { Sweden. }\end{array}$ & $\begin{array}{l}\text { Alkit } \\
\text { Communications }\end{array}$ & $\begin{array}{c}\text { Software and services focusing } \\
\text { on data collection and } \\
\text { analytics }\end{array}$ \\
\hline \multirow[t]{2}{*}{ Musselfeed AB } & $\begin{array}{l}\text { Mussel producer with unique } \\
\text { shell seperation methods. }\end{array}$ & Armatec & $\begin{array}{l}\text { Pump, valve and control } \\
\text { systems within flow } \\
\text { technology }\end{array}$ \\
\hline & & Minesto & $\begin{array}{l}\text { 'Deep green' electricity } \\
\text { solution via underwater kite }\end{array}$ \\
\hline
\end{tabular}

One clear hindrance is the scalability of the marine food group and its entrepreneurial actors, which has been attributed to the reliance of the KIEs on larger actors to produce the scale economies necessary to establish the new techniques as competitive on the market. Policy support and bureaucracy have not been supportive enough of this development, and there has been a lack of prioritization of aquaculture activities over or on equal terms with other green solutions in the food industry. Moreover, it has been expressed that these small solution providers need to be able to grow and scale up on their own in order to match the international competition, or to become vertically integrated into other larger companies active in the sector [36]. In both cases, there is a greater need to understand which types of firms need to undertake which types of long-term strategic actions in order to maximize both private and public outcomes.

In the maritime energy group, most KIEs currently fill the role of basic and/or applied research and development, as well as the design and construction of solution-based products and services (SeaTwirl, Hexicon, Roxtec, and Greenpipe for example). The large-scale development activity of projects, construction, installation, service and maintenance, and deconstruction is left mainly to larger actors, such as formerly public local giants such as Vattenfall, and Sweden-based multinational actors like ABB, E.On, and Stena Recycling. The role of the KIEs seems here to be largely that of pushing the technology into new areas, which can then later be integrated into the larger framework of multinational and regional government activities [37].

In order to elucidate further the collaboration and linkages between collective action, knowledge, returns, and the loop mechanism leading to SDGs and then back to collective action through S3, we would like to spend some time illustrating what has happened through two case studies of the abovementioned firms, one from each of the selected groups. 
Minesto is a firm in the marine energy cluster. Founded in 2007, the firm was spun out of SAAB, Sweden's foremost aerospace and defense company whose name is commonly associated with automobile production. The technology that Minesto is built around was developed by a SAAB engineer in 2006, and in 2007, the firm was founded by an entrepreneurship student from Chalmers University of Technology in Gothenburg. The initial phase of this happened through a Master thesis project in which a student and the thesis supervisor (who became the future founder) assessed the commercial application of the technology. This occurred together with the help of Midroc New Technology, a portfolio investment company, and Chalmers Ventures, the incubator and entrepreneurship support office at Chalmers. Saab spun out the idea, as it did not appear that there were the necessary resources in place for commercialization under their brand. Around the same time, more private equity flowed into the Minesto from Verdane, an investment firm, and Vinnova, the Swedish agency for innovation. Minesto launched an initial public offering (IPO) in 2016 and in 2017 began a launch plan for its main product, an underwater energy-generating kite powered by 'deep green' technology. Minesto describes the technology as follows [38]:

"The underwater current creates a hydrodynamic lift force on the wing (1) which pushes the kite upwards. The kite is steered in an eight-shaped trajectory by a rudder and reaches a speed several times the actual stream speed (2). As the kite flies in the current, water flows through the turbine at the same speed and electricity is produced in the generator (3). The electricity is transmitted through a cable in the tether attached to the wing (4). The electricity continues via cables on the seabed to grid on shore (5)."

Since its IPO, the firm has expanded internationally to offices in the UK and established a presence in Taiwan. However, the commercial product in the form of the deep green kite is still as of writing not on the market.

We now turn to an exemplary firm in the marine foods group. Swedish Algae Factory is a firm that has a similar origin story to that of Minesto. It started with a scientific breakthrough by a professor at the University of Gothenburg, who together with others in her field made a discovery relating to the versatility of a particular type of marine and freshwater algae, diatoms. By extracting frustules, or the external layer, from diatoms, through an industrial biofilm process, various applications are possible, including uptake of energy, chemicals or mechanical waves [39]. Similar to Minesto, a Masters student at the Chalmers University of Technology saw potential in commercializing the scientific discovery and its application to solar panels, marine food production, and personal care products. In 2016, the venture was founded and currently receives funding from several regional actors (EU life, the European Institute of Innovation and Technology, and Horizon 2020), as well as several national actors (the Swedish Energy Agency Energimyndigheten and the Swedish Innovation Agency Vinnova). Additionally, the firm The Swedish Algae Factory is also partnered with another venture we have identified, Smögenlax, as an algae-based fish food provider linking into Smögenlax's circular no-waste salmon production system in Lysekil county, Sweden.

In August 2018, the Swedish Algae Factory expanded its algae production with a 300 square meter facility, with plans to scale up even more and establish international production locations in the near future.

Shown in Table 2 above, these two firms have strikingly similar paths of development but have employed entirely different types of technology and show, in our view, very different aspirations in terms of strategic development and growth trajectories. Table 2 illustrates each from a more systemic perspective, including interactions, collaborations, pathways, and how the innovation being produced contributes to sustainable development goals. Both ventures have involved the commercialization of a technology, one at a multinational company, the other at a university department. Both were then used in a venture creation program at the Masters level, where in one case, the student became the CEO (SAF), while in the other, the supervisor of the thesis project became the CEO (Minesto). In both cases, the origination location of the idea remained involved throughout the process and still is 
today. However, the commercialization phases of the two are quite different. Minesto has yet to offer their product for sale and is still beta-testing its Deep Green kite, whereas SAF have begun to sell to a number of different markets and are actively pursuing an expansion strategy. As far as the authors can tell, Minesto's internationalization strategy rests on an initiative to procure additional resources in advance of commercialization, i.e., opening doors to new markets by establishing a presence there.

Table 2. Contrasting firm characteristics in two maritime sectors.

\begin{tabular}{ccc}
\hline & Swedish Algae Factory (SAF) & Minesto \\
\hline S3 Group & Marine Foods & Marine Energy \\
\hline Product offering & $\begin{array}{c}\text { Circular algae cultivation; controlled } \\
\text { algae bloom producing shell materials } \\
\text { for multiple application areas. }\end{array}$ & $\begin{array}{c}\text { 'Deep green' electricity solution via } \\
\text { underwater kite }\end{array}$ \\
\hline $\begin{array}{c}\text { Key university } \\
\text { collaborations/partnerships }\end{array}$ & $\begin{array}{c}\text { Chalmers University of Technology; } \\
\text { University of Gothenburg }\end{array}$ & Chalmers University of Technology \\
\hline $\begin{array}{c}\text { Key international and } \\
\text { national partners }\end{array}$ & EIT, Horizon 2020, EU life & $\begin{array}{c}\text { EIT, European Regional } \\
\text { Development Fund, Horizon 2020 }\end{array}$ \\
\hline $\begin{array}{c}\text { Key multinational } \\
\text { collaborations/partners }\end{array}$ & Abba Seafood & SAAB Aerospace \\
\hline $\begin{array}{c}\text { Key regional and } \\
\text { communal partners }\end{array}$ & $\begin{array}{c}\text { Lysekil county, Swedish innovation } \\
\text { agency, Swedish energy agency }\end{array}$ & $\begin{array}{c}\text { Swedish innovation agency } \\
\text { Commercialization phase } \\
\text { of product }\end{array}$ \\
$\begin{array}{c}\text { Products on market in various forms: } \\
\text { Skin care, biofood, wastewater } \\
\text { treatment. }\end{array}$ & $\begin{array}{c}\text { Product in testing, not yet } \\
\text { commercialized. }\end{array}$ \\
\hline $\begin{array}{c}\text { Patent progress } \\
\text { Innovative contributions to } \\
\text { SDGs (potential) }\end{array}$ & $\begin{array}{c}\text { Circular algae cultivation with } \\
\text { sustainably produced areas of } \\
\text { application (inter alia SDG 8, 12, } \\
\text { 13, 14, 15) }\end{array}$ & $\begin{array}{c}\text { So far untapped renewable energy } \\
\text { resources generating electricity from } \\
\text { the ocean (inter alia SDG 8, 14) }\end{array}$ \\
\hline
\end{tabular}

One thing that is consistent between the two examples is the nature of the products and services the firms are generating. Both of these KIE firms use innovation as a means of attempting to directly impact, and thus forward progress towards, sustainable development goals. Web materials from both companies indicate a heightened awareness towards sustainability and sustainable development, and the nature of their product offering reflects this stance.

Now we may link what we have exemplified here back to our conceptual framework in Figure 2. In both examples, and in many others within the two groups, the innovative process of the firms equates to a collective action process through which scientific and technological inputs are transformed into product and service offerings. Through the constant monitoring process employed throughout the S3 sector by actors like the EU, private investment firms, multinational stakeholders, as well as regional actors like VGR, Offshoreväst, and the Maritime Cluster, activities are legitimized and able to be competitive enough to (in theory) generate substantial private returns which KIEs can reinvest. Additionally, public returns are generated through increasing the likelihood of SDG fulfillment as realized through product and service innovation by KIE firms. Both of these types of returns thus are contributing to, or have the potential to contribute to, numerous sustainable development goals. This process creates a loop back to the renewed generation of collective action for science in technology through the knowledge or at least temporary assurance that these solutions have a place within the economic system. In truth, subsidies and funding offered through the S3 projects directly renew incentives for KIE firms to innovate and experiment within this cluster.

From analyzing the case studies, we can see that a key point is that within the same S3 area, there is a vast difference between what types of KIEs can exist. The S3 area of maritime business is 
broad and encompasses a wide range of sectors, all of which have different conditions, opportunities, and incentives for knowledge-intensive and innovative entrepreneurship. This can range from the focus on different types of specific knowledge and knowledge-intensity, what types of other sectors and industries are producing this knowledge or if it is generated in house, and whether it is science-based or more applied technical knowledge. Moreover, the strategies for commercialization of innovations and/or novel use of existing knowledge that will be or could be optimal for marine feeds startups can be radically different from those involved in marine energy, both in terms of inputs as well as outputs. Knowledge-intensive entrepreneurship provides tools and a conceptualization to address this variation.

Additionally, we argue that the monitoring of the collaboration occurring, which leads to public ratification of an idea, such as sustainability, plays a decisive role in making these ventures lucrative endeavors to begin with. Some degree of institutional acceptance is needed for the goods to have value that outweighs less sustainable alternatives like fossil fuels or waste-generating food production. For instance, a mussel produced according to the principles of a circular economy is, at the end of the day, very likely comparable in taste and consistency to a mussel produced without this process and probably costs considerably more to produce. However, it can be argued that the way in which it was produced holds both a social and an economic value that is a result of the normative and institutional context surrounding its production.

If one refers back to Figure 2, we can see that each of the KIE firms we have discussed finds themselves in a different segment of our conceptualization. Minesto, though active in expansion and technological development, has yet to offer their product for sale, so their direct impact on SDGs may still be yet to emerge. They find themselves predominantly in the bottom left portion of Figure 2 . On the other hand, SAF have commercialized successfully, are obtaining substantial capital investment, and are active on several different markets, as intermediaries of production (i.e., in collaboration with Smögenlax in Lysekil) as well as direct sellers (solar energy, skin care). Their innovations are already contributing to SDGs as we see it. How this is affecting the smart specialization strategies in terms of creating a circular loop to feed into new products and services being collectively developed by other startups, researchers, universities, or multinationals, remains to be seen.

Thus, we propose that an in-depth knowledge of KIE theory can help to guide decision making in this and other S3 areas, given that the S3 policy movement is closely related with the Europe 2020 strategy towards smart, sustainable, and inclusive growth [7]. The final section reflects on what these activities based in the revised conceptual framework mean for policy makers, and how future research on KIE's link to S3 and fulfillment of SDGs can progress further.

\section{Conclusions and Future Research}

This article is both explorative and conceptual, where we suggest that the concept and phenomenon of knowledge-intensive entrepreneurship can be used to further develop public policy for transformative change. The literature on S3 has stressed the interplay between new firms, old firms, and the state, and not only in high-tech industries [5,21]. The literature on KIE also stresses interplays, and especially how a wider ecosystem helps to provide stimuli and resources for the creation of new KIE firms [2].

Our main message is that smart specialization principles, when integrated with the concept of knowledge-intensive entrepreneurship, can guide these interactions and trajectories and by doing so enhance the likelihood of (partial) fulfillment of sustainable development goals of the EU and therefore pave the way to driving forward the prescribed notion of a more transformative innovation policy agenda [9]. Transformative implications can thus be derived from these pathways/principles, including the role of entrepreneurship, the state, and industry MNEs in creating new forms of co-collaboration within the wider entrepreneurial ecosystem.

Specifically, we see KIE as a catalyst in transforming economic activity in the new economy and thus necessary to further consider in relation to S3 and public policy. Therefore, specifically in this article, we developed a process model over time of the relationships between private and public 
returns. In Figure 2 above, we proposed that there is an overlap of private and public returns in the specific case of sustainability, as well as a feedback loop between sustainability and the generation of further collective action for science and technology. Our view is that having activities in a region which generates a wider set of activities on the left side of Figure 2 will in turn enable societal creation of knowledge, useful for both public returns and for private returns through KIE. In this process view, we stress that the model illustrates some of the underlying dynamics of continuing to introduce new scientific and technological knowledge that is relevant for solving the problems of sustainability.

Our position is that this more complex view will help policy makers and researchers to identify the opportunity sets for KIE across the economy. By interacting and collaborating within the S3 system, policy makers will learn more about what does and does not work for KIE firms, what they need, and how they should grow. This will lead to different sets of outcomes for different S3 areas, different regions, and different configurations of actors. However, it is crucial that from a policy standpoint, the interplay between KIE and S3, and how it can result in sustainable development outcomes, is of paramount importance. We argue for a new combination of the two concepts, as done here.

Therefore, we propose from this case that there are at least three different types of trajectories (cumulative feedback loops) over time, which could stimulate KIE firms. Future research should determine the likelihood of them occurring, under different initial conditions and as associated with different policy instruments. The KIE firm should be understood in relation to the development of new scientific and technological knowledge for sustainability, and in such a way that KIE firms are seen in relation also to the policy makers/state actors, and the established, likely multinational, boundary-spanning enterprises which operate in a given region.

We propose one main role of KIE, set within the concept of S3 policies and sustainability. This main role is to generate experimentation in the economy [2,40]. They provide new ideas and test towards the market, and in ways that can achieve wider sustainability goals. We have shown in our illustration that many small KIE firms are started with goals that would not have been possible through market forces alone.

We propose three differing roles of KIE are possible, which indicate different trajectories for regions under S3 policies. They are as follows:

1. KIEs as knowledge banks to be tapped into and experimental actors.

By this, we mean that policy can give KIE the means to experiment and follow their progress with new use and application of new technologies. There may be a particular role of local and global MNEs. We suggest that the MNEs may stand at the sidelines, using the KIE to search instead of their own R\&D, and then later, when new technological of relevance emerge, then they acquire promising KIE firms. This is very important for the S3 processes, because the KIE firms introduces the novelty, whereas the MNE commercializes in a larger scale, and by acquiring them, doing so in attempt at internalizing their 'knowledge intensity'. The implication is that public policy, by focusing on sustainability, has opened up new opportunity spaces for experimentation, which are filled by a variety of KIE firms.

2. KIEs as growing into medium and large players themselves.

A different trajectory, taking more time, is growth through the KIE. Previous research suggests that rapid growth is a relatively rare event for this type of firm, but the ones who do show great potential to impact the economy. We recommend that policy makers give KIE firms the support structures they need to grow, while KIE forge alliances and extended networks with MNEs, leading to potential high growth and development. KIEs constitute market creators and potential future competitive multinationals. The implication for public policy is to occasionally concentrate resources on a few KIE firms with high potential, but with the acknowledgement that some of them will fail as well.

3. KIEs stay small but integrate into global value chains. 
KIE may also be highly specialized knowledge-providers, which may also materialize as a provider of manufactured components, services, or knowledge. They may therefore also remain small but highly globally connected. We recognize that this requires collaborative or partnership-based work with the multinational enterprises. The negative side may be that these firms become so specialized that they move to more regions with a higher number of innovative and dense networks connections within a specialized area. The extent of global value chain dynamics in a given specific location remains an unknown variable in this equation. The implication for public policy actors is finding a balance of capabilities, incentives to collaborate, and a schema of potential desirable outcomes to strive for.

We would like to address, if somewhat speculatively, how these strategies have played out for the two illustrative companies described in this article, Minesto and the Swedish Algae Factory. At present, Minesto finds itself as a likely candidate for the first strategy; that is, a venture that will stay small and produce a single (or a select few) technology-intensive, and expensive, product for a particular niche market. However, it might find itself shifting into the third strategy, given that it can forge and maintain international and regional partnerships with the larger actors in the energy industries of Europe and Asia, for a start. The Swedish Algae Factory seems like a prime candidate for the second strategy, that is, growing into a large player in its own right. The company has been adamant about its expansion goals and the scalability of its science lab and its algae growing activities. Time will tell if this expansion will happen or not, but it remains a strategic goal.

Regarding how these possibilities play out in the groups, overall, it is clear that 1 and 3 are the potentially dominant ones; however, there are indications that the marine foods sector needs scalable KIE companies in order to be able to compete internationally. The report referenced above argues that policy makers need to prioritize and encourage aquaculture development in a similar fashion to land-based green food solutions. However, this strategy might overall be less relevant for marine energy KIE firms, due to the fact that achieving scalability is much more resource-intense and potentially better left to large industrial players, MNEs, and the local government. However, the question remains whether it is in the long run more beneficial for larger industrial actors to acquire the technology or the KIE firm itself and internalize production, or whether the KIE should 'stay small' as indicated above. This has implications for smart specialization strategy at the regional and, likely, the national and global level.

Our recommendation is therefore that public policy for S3 can become better, with specific attributes of different types of knowledge development. By understanding sector-specific needs of knowledge-intensive entrepreneurship, and understanding that within an S3 area, there can be radically different strategic goals, and needs, of knowledge-intensive entrepreneurial ventures, policy makers can better identify and better configure SME and entrepreneurship policy, translating into more precise and measurable policy tools and assessments. One instance where it could be relevant, given the above literature review, is that by taking into account in more detail needs of the types of KIE firms that are prominent in a given area, i.e., the role of such types of key determinants of entrepreneurship strategy as diversification activities and technology congruence with other industries [24], policy makers can avoid these types of top-down practices, whether planned or not planned, becoming too overbearing.

Even though in the selected groups illustrated, in this case, the system seems to be working reasonably well in terms of addressing the need of the region and acknowledging the role of the entrepreneur, more is needed in terms of organizing collective action to address the fulfillment of the relevant SDGs, not least for marine foods. By using KIE theory to better understand the origins and aspirations of the KIE firms within the group, and what particular type of knowledge-intensive entrepreneurship is filling the experimentation role in the area, whether it be firms that are using, applying, creating, or co-developing new scientific and/or technological knowledge, policy makers can obtain more and better information about what challenges they are able to solve and how they ideally can be linked to the S3 constellation of actors. For instance, there remains an overarching collective action challenge in marine foods, due to the group receiving very limited attention in the broader global policy realm as a solution to the extraordinary needs of the growing global population, one which many 
argue can be filled largely by this group $[35,36]$. By more systematically understanding the nature and the mechanisms by which KIE firms both within and outside of a group like marine foods contribute to that group, and how their needs and strategies are intertwined with MNEs, local research institutes and universities (for instance), better policies can be designed to address this. As referenced earlier, independent technologies will likely only contribute to sustainability goals when complementary technologies and institutions also become available in this larger sociotechnical system [12], and in this illustration, we have outlined how this has happened, or is poised to happen, in the S3 area of marine activities in West Sweden.

Regardless, these three different principles outlined above can serve as an initial roadmap for policy makers to assess what types of regional entrepreneurship configurations are needed depending on sector/industry boundaries and overlaps, and the potential for different types of diversification at the appropriate level which they need to be addressing.

Author Contributions: Conceptualization, E.G. and M.M.; Writing—original draft, E.G. and M.M.; Writing一review and editing, E.G. and M.M.

Funding: This research was funded by the Swedish Research Council Distinguished Professor's Programme, awarded to Professor McKelvey, grant number VR DNR 2017-03360.

Conflicts of Interest: The authors declare no conflict of interest. The funders had no role in the design of the study; in the collection, analyses, or interpretation of data; in the writing of the manuscript, or in the decision to publish the results.

\section{References}

1. Ljungberg, D.; McKelvey, M. What Characterizes Firms' Academic Patents? Academic Involvement in Industrial Inventions in Sweden. Ind. Innov. 2012, 19, 585-606. [CrossRef]

2. Malerba, F.; McKelvey, M. Knowledge-intensive innovative entrepreneurship integrating Schumpeter, evolutionary economics, and innovation systems. Small Bus. Econ. 2018, in press. [CrossRef]

3. Lassen, A.H.; McKelvey, M.; Ljungberg, D. Knowledge-intensive entrepreneurship in manufacturing and creative industries: Same, same, but different. Creat. Innov. Manag. 2018, 27, 284-294. [CrossRef]

4. McKelvey, M.; Zaring, O.; Szücs, S. Conceptualizing evolutionary governance routines: Governance at the interface of science and technology with knowledge-intensive innovative entrepreneurship. J. Evol. Econ. 2019, in press. [CrossRef]

5. Foray, D. Smart Specialization Strategies as a Case of Mission-oriented Policy: A Case Study on the Emergence of New Policy Practices. Ind. Corp. Chang. 2018, 27, 817-832. [CrossRef]

6. McCann, P.; Ortega-Argiles, R. Smart specialisation, entrepreneurship and SMEs: Issues and challenges for a results-oriented EU regional policy. Small Bus. Econ. 2016, 46, 537-552. [CrossRef]

7. European Community. Europe 2020: A European Strategy for Smart, Sustainable and Inclusive Growth; EU: Luxembourg, 2010.

8. OECD. Better Policies for Sustainable Development 2016: A New Framework for Policy Coherence; OECD: Paris, France, 2016.

9. Schot, J.; Steinmueller, W.E. Three frames for innovation policy: R\&D, systems of innovation and transformative change. Res. Policy 2018, 47, 1554-1567. [CrossRef]

10. EU. Sustainable Development in the European Union: Monitoring Report on Progress towards SDGs in an EU Context; EU: Luxembourg, 2017.

11. Köhler, J.; Geels, F.; Kern, F.; Markard, J.; Onsongo, E.; Wieczorek, A.; Alkemade, F.; Avelino, F.; Bergek, A.; Boons, F.; et al. An Agenda for Sustainability Transitions Research: State of the Art and Future Directions. Environ. Innov. Soc. Transit. 2019, 31, 1-32. [CrossRef]

12. Bijker, W.; Hughes, T.; Pinch, T. The Social Construction of Technological Systems: New Directions in the Sociology and History of Technology, Anniversary Edition; The MIT Press: Cambridge, MA, USA, 2012.

13. Elzen, B.; Geels, F.; Green, K. System Innovation and the Transition to Sustainability: Theory, Evidence and Policy; Edward Elgar: Cheltenham, UK, 2004.

14. Mazzucato, M. From market fixing to market-creating: A new framework for innovation policy. Ind. Innov. 2016, 23, 140-156. [CrossRef] 
15. Foray, D.; David, P.; Hall, B. Smart Specialisation: From Academic Idea to Political Instrument, the Surprising Career of a Concept and the Difficulties Involved in its Implementation; EPFL, Ed.; EPFL: Lausanne, Switzerland, 2011.

16. Florida, R. The Flight of the Creative Class: The New Global Competition for Talent; Routledge: London, UK, 2006.

17. Baumol, W.J. Entrepreneurship: Productive, unproductive, and destructive. J. Bus. Ventur. 1996, 11, 3-22. [CrossRef]

18. Trajtenberg, M. Innovation Policy for Development: An Overview. In The New Economics of Technology Policy; Foray, D., Ed.; Edward Elgar: Cheltanham, UK, 2009; pp. 409-415.

19. Uyarra, E. Smart specialization as Place-based Policy. Lessons Learnt? Reg. Insights 2019, 1-6. [CrossRef]

20. Hausmann, R.; Rodrik, D. Economic Development as Self-Discovery. J. Dev. Econ. 2003, 72, $603-633$. [CrossRef]

21. Foray, D. Smart specialisation strategies and industrial modernisation in European regions-theory and practice. Camb. J. Econ. 2018, 42, 1505-1520. [CrossRef]

22. Foray, D. On Sector-non-neutral Innovation Policy: Towards New Design Principles. J. Evol. Econ. 2018, in press. [CrossRef]

23. Smith, K. Innovating for the global commons: Multilateral collaboration in a polycentric world. Oxf. Rev. Econ. Policy 2017, 33, 49-65. [CrossRef]

24. Balland, P.-A.; Boschma, R.; Crespo, J.; Rigby, D.L. Smart Specialization Policy in the European Union: Relatedness, Knowledge Complexity and Regional Diversification. Reg. Stud. 2018, 1-17, in press. [CrossRef]

25. Iacobucci, D.; Guzzini, E. Relatedness and Connectivity in Technological Domains: Missing Links in S3 Design and Implementation. Eur. Plan. Stud. 2016, 24, 1511-1526. [CrossRef]

26. Caffano, M.; Foray, D. The Centrality of Entrepreneurial Discovery in Building and Implementing a Smart Specialisation Strategy. Ital. J. Reg. Sci. 2014, 13, 33-50. [CrossRef]

27. Godin, B. The Knowledge-Based Economy: Conceptual Framework or Buzzword? J. Technol. Transf. 2006, 31, 17-30. [CrossRef]

28. Tether, B.S. Services, innovation, and managing service innovation. In The Oxford Handbook of Innovation Management; Dodgson, M., Gann, D.M., Phlips, N., Eds.; Oxford University Press: Oxford, UK, 2014; pp. 600-624.

29. AEGIS Research Project. Advancing Knowledge-Intensive Entrepreneurship and Innovation for Economic Growth and Social Well-Being in Europe; European Commission: Brussels, Belgium, 2013.

30. Malerba, F.; Caloghirou, Y.; McKelvey, M.; Radosevic, S. (Eds.) Dynamics of Knowledge-Intensive Entrepreneurship: Business Strategy and Public Policy; Routledge: London, UK, 2016.

31. Nelson, R.R.; Winter, S.G. An Evolutionary Theory of Economic Change; Belknap Press of Harvard University Press: Cambridge, MA, USA, 1982.

32. Gifford, E. Exploring Knowledge Intensity in Entrepreneurship: A Quantitative Study of Knowledge, Innovation and Performance in Entrepreneurial Firms; University of Gothenburg: Gothenburg, Sweden, 2017.

33. McKelvey, M.; Ljungberg, D. How public policy can stimulate the capabilities of firms to innovate in a traditional industry through academic engagement: The case of the Swedish food industry. RD Manag. 2017, 47, 534-544. [CrossRef]

34. Ostrom, E. Governing the Commons: The Evolution of Institutions for Collective Action; Cambridge University Press: Cambridge, UK, 1990.

35. Västra Götalands Regionen. Hållbara Maritima Näringar; Västra Götalands Regionen: Gothenburg, Sweden, 2019.

36. Maritime Cluster in West Sweden. Ur hav och Sjö Växer Framtidents Näring; Västra Götalands Regionen: Gothenburg, Sweden, 2018.

37. OffshoreVäst. Vindenergi till Havs: Ett Projekt inom Offshoreväst; OffshoreVäst: Gothenburg, Sweden, 2019.

38. Minesto. Our Technology. Available online: https://minesto.com/our-technology (accessed on 23 August 2019).

39. Allert, S.; Wulff, A. Frustules Extracted from Benthic Pennate Diatoms Harvested from an Industrial Biofilm Process. U.S. Patent 2019/0106672 A1, 17 April 2019.

40. Kerr, W.R.; Nanda, R.; Rhodes-Kropf, M. Entrepreneurship as Experimentation. J. Econ. Perspect. 2014, 28, 25-48. [CrossRef]

(C) 2019 by the authors. Licensee MDPI, Basel, Switzerland. This article is an open access article distributed under the terms and conditions of the Creative Commons Attribution (CC BY) license (http://creativecommons.org/licenses/by/4.0/). 